\title{
Percentile indices for assessing changes in heavy precipitation events
}

\author{
Christoph Schär ${ }^{1} \cdot$ Nikolina Ban $^{1} \cdot$ Erich M. Fischer ${ }^{1}$. \\ Jan Rajczak ${ }^{1}$ - Jürg Schmidli ${ }^{2}$. Christoph Frei $^{3}$ • \\ Filippo Giorgi ${ }^{4}$ - Thomas R. Karl ${ }^{5}$. \\ Elizabeth J. Kendon ${ }^{6}$ • Albert M. G. Klein Tank ${ }^{7}$ • \\ Paul A. O'Gorman ${ }^{8}$. Jana Sillmann' ${ }^{9}$ Xuebin Zhang ${ }^{10}$. \\ Francis W. Zwiers ${ }^{11}$
}

Received: 16 May 2015 / Accepted: 16 March 2016/Published online: 5 April 2016

(C) The Author(s) 2016. This article is published with open access at Springerlink.com

\begin{abstract}
Many climate studies assess trends and projections in heavy precipitation events using precipitation percentile (or quantile) indices. Here we investigate three different percentile indices that are commonly used. We demonstrate that these may produce very different results and thus require great care with interpretation. More specifically, consideration is given to two intensity-based indices and one frequency-based index, namely (a) all-day percentiles, (b) wet-day percentiles, and (c) frequency indices based on the exceedance of a percentile threshold.
\end{abstract}

Christoph Schär

schaer@env.ethz.ch

1 Institute for Atmospheric and Climate Science, ETH Zürich, Universitätsstr. 16, 8092 Zürich, Switzerland

2 Goethe-University, Frankfurt am Main, Germany

3 Federal Office of Meteorology and Climatology MeteoSwiss, Zürich, Switzerland

4 Abdus Salam International Centre for Theoretical Physics, Trieste, Italy

5 National Center for Environmental Information, NOAA, Asheville, NC, USA

6 Met Office Hadley Centre, Exeter, UK

7 Royal Netherlands Meteorological Institute (KNMI), De Bilt, Netherlands

8 Department of Earth, Atmospheric and Planetary Sciences, MIT, Cambridge, MA, USA

9 CICERO Center for International Climate and Environmental Research, Oslo, Norway

10 Climate Research, Environment and Climate Change Canada, Toronto, ON, Canada

11 University of Victoria, Victoria, BC, Canada 
Wet-day percentiles are conditionally computed for the subset of wet events (with precipitation exceeding some threshold, e.g. $1 \mathrm{~mm} / \mathrm{d}$ for daily precipitation). We present evidence that this commonly used methodology can lead to artifacts and misleading results if significant changes in the wet-day frequency are not accounted for. Percentile threshold indices measure the frequency of exceedance with respect to a percentile-based threshold. We show that these indices yield an assessment of changes in heavy precipitation events that is qualitatively consistent with all-day percentiles, but there are substantial differences in quantitative terms. We discuss the reasons for these effects, present a theoretical assessment, and provide a series of examples using global and regional climate models to quantify the effects in typical applications.

Application to climate model output shows that these considerations are relevant to a wide range of typical climate-change applications. In particular, wet-day percentiles generally yield different results, and in most instances should not be used for the impact-oriented assessment of changes in heavy precipitation events.

\section{Introduction}

There is increasing evidence that anthropogenic climate change leads to an intensification of the water cycle and attendant effects on heavy and extreme precipitation events. The 5th assessment report of the IPCC (2013) concludes that the frequency and intensity of heavy precipitation events have likely increased in a number of areas, among these North America and Europe, and it projects that heavy precipitation events over most of the mid-latitude land masses and over wet tropical regions will become more intense and frequent by the end of this century. These changes are important for a number of potential impacts, including floods, erosion, water resources, agriculture and ecosystems.

Past studies have used a number of statistical methodologies to assess changes in heavy precipitation events in long-term observational rain gauge series and climate simulations. Some of the early studies in this area (e.g. Noda and Tokioka 1989; Gordon et al. 1992; Fowler and Hennessy 1995) typically defined 5 to 8 intensity classes, and addressed changes in each of these. As the classes are subjectively selected, the choice may suit a certain region but miss the heavy events of another, due to tremendous geographical variations.

Subsequent studies have thus attempted to make the analyses more versatile with respect to the wide range of climates that need to be considered. Simple indices that have been considered include the average yearly or seasonal maximum 1-day precipitation amount (e.g. Räisänen and Joelsson 2001), or exceedance counts with respect to carefully selected thresholds. More sophisticated methodologies include statistical analysis using a gamma distribution (e.g. Gregory and Mitchell 1995; Groisman et al. 1999; Voss et al. 2002; Zolina et al. 2009), or the application of extreme value theory (EVT, e.g. Zwiers and Kharin 1998; Frei et al. 2006; Fowler et al. 2007). Many of these studies employ a mixed statistical model (for instance a binary distribution for precipitation occurrence, and a gamma distribution for precipitation amounts). Such methodologies have successfully been applied in a number of studies and are particularly common in water resource engineering applications.

In this study we are concerned with percentile indices. These indices are used to address moderate to heavy precipitation events, i.e. precipitation events that are larger than average events (that may be assessed by their mean daily intensity), but smaller than rare extremes (that require more sophisticated statistical approaches). They are popular because they combine simplicity with flexibility. In particular, one single percentile index is able to assess changes in heavy events in vastly different climatic conditions (e.g. Suppiah and Hennessy 1998). Percentile indices are 
also used to assess process-based interpretations of precipitation events with the ClausiusClapeyron relationship (e.g. Frei et al. 1998; Allen and Ingram 2002; Ban et al. 2015), and in statistical downscaling and bias correction methodologies (Maraun et al. 2010).

The use of precipitation percentiles in the literature exhibits a number of different methodologies. Here we investigate three types of percentile indices:

a) All-day percentiles (e.g. Moberg et al. 2006; O'Gorman and Schneider 2009; O'Gorman 2014; Ban et al. 2015): In this case the percentiles are expressed relative to all data, i.e. wet and dry days or hours. Changes in all-day percentile indices are directly related to changes in heavy events with a given absolute frequency (or return period), and may be viewed as an empirical alternative to EVT in the case of moderate extremes.

b) Wet-day percentiles (e.g. Boroneant et al. 2006; Frei et al. 2006; Lenderink and van Meijgaard 2008; Rajczak et al. 2013; Kendon et al. 2014). In this case precipitation percentiles are computed for the subset of days or hours with non-zero precipitation, i.e. with precipitation above daily or hourly thresholds of typically $1 \mathrm{~mm} / \mathrm{d}$ or $0.1 \mathrm{~mm} / \mathrm{h}$, respectively. These thresholds have been motivated from observational constraints.

c) Frequency indices based on percentile thresholds (e.g. Karl and Knight 1998; Frei and Schär 2001; Durman et al. 2001; Klein Tank and Können 2003; Orlowsky and Seneviratne 2012; Sillmann et al. 2013; Giorgi et al. 2014): In this case, percentile thresholds are derived for some reference period, and the subsequent analysis then targets the frequency with which these thresholds are exceeded. This procedure corresponds to the official recommendation of the World Climate Research Program (WCRP) and the World Meteorological Organization (WMO 2009; Zhang et al. 2011). The methodology does not fully classify as a percentile methodology; it rather corresponds to a frequency methodology, but using a percentile-based definition of the thresholds.

Many studies have used a combination of percentile indices. For instance, Karl and Knight (1998) used both frequency and intensity-based indices and found that the observed precipitation increase of about $10 \%$ across the contiguous United States is primarily due to increases in heavy and extreme daily precipitation events. Other studies used wet-day percentiles in the analysis of precipitation scaling, but all-day percentiles when assessing climate change simulations, because "it is the absolute frequency of occurrence of extremes that counts for society" (Lenderink and van Meijgaard 2008). There are also a number of studies that do not explicitly specify the type of percentiles used.

Here we will present a theoretical analysis and an intercomparison of percentile indices using typical climate change applications. It will be shown that in general the three types of indices yield different results. In particular, we show that changes in the frequency of wet days (or wet hours) may potentially lead to misleading results when addressing changes in heavy precipitation events using wet-day percentile indices.

Difficulties with wet-day percentiles have previously been noted. In particular, Hennessy et al. (1999) pointed out that changes in observational precipitation thresholds associated with switching from imperial to metric units introduced apparent trends in the number of raindays. Shortly thereafter, Haylock and Nicholls (2000) provided a thorough discussion of the role of the wet-day thresholds and concluded that percentile indices can be sensitive to changes in the number of raindays. However, the sensitivity revealed did not appear alarming, as observational precipitation series with comparatively small trends in wet-day frequency were used. In the climate change context, however, it is evident that changes in wet-day frequency are 
substantial (e.g. Rajczak et al. 2013) and may dominate changes in precipitation totals over much of the subtropics (Polade et al. 2014).

Some previous work has also addressed challenges with yet another percentile index, namely the fraction of precipitation that falls above the 95th wet-day percentile (commonly referred to as the R95pTOT index). In particular Zolina et al. (2009) and Leander et al. (2014) have investigated the statistical properties of this index, and have proposed alternate versions thereof. In the current paper we will restrict attention to the basic form of the percentile indices.

The outline of the paper is as follows: Section 2 provides an overview of the three precipitation percentile indices and investigates potential artifacts in a conceptual and theoretical framework. Section 3 provides examples and an intercomparison of different percentile indices using output from a number of GCM and RCM experiments. Section 4 concludes the study. For most of the paper (except for section 3.3), consideration is given to the statistics of daily events, but the concepts can also be applied to shorter accumulation periods, such as hourly data.

\section{Analysis of percentile methodologies}

Precipitation percentile indices are generally computed from long series of precipitation data. To compute the percentiles, the data is sorted in ascending order, and the resulting distribution can be interpreted as a representation of the frequency-intensity relation of precipitation. In this section we discuss the three categories of percentile indices using daily precipitation accumulations to define events and indices. The indices are discussed along Fig. 1a-c, respectively, where precipitation percentiles $P[\mathrm{~mm} / \mathrm{d}]$ are shown as a function of cumulative probability $g$. We will use the inverse cumulative distribution function $P(g)$, where $g$ is a probability variable ranging from 0 to 1 . In a statistical sense, daily precipitation is expected to exceed $P(g)$ with an absolute frequency of $F=1-g$, and to fall below $P(g)$ with a probability of $g$.
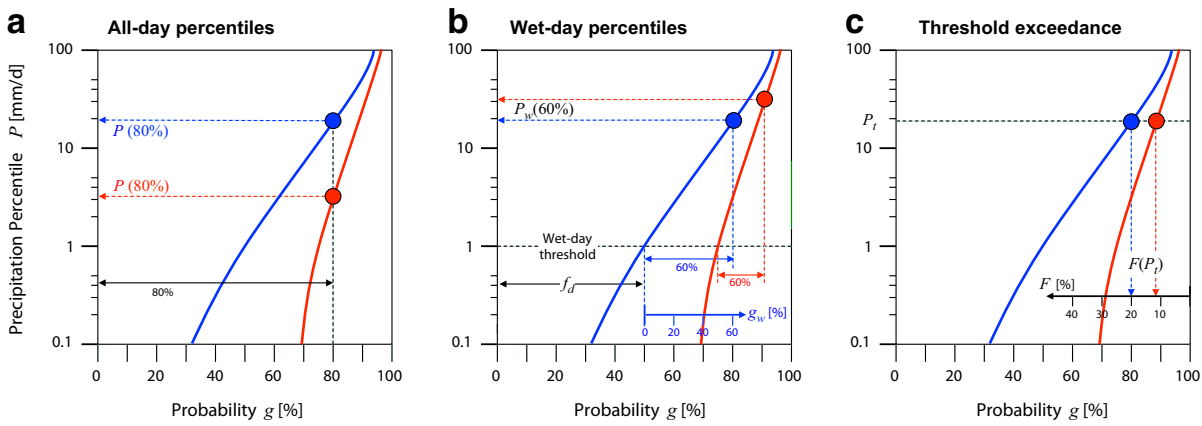

Fig. 1 Schematic illustration of three different percentile indices, with precipitation percentiles shown as a function of cumulative probability g: (a) All-day percentiles: percentiles are computed with respect to all days. (b) Wet-day percentiles: percentiles are computed with respect to wet days $(>1 \mathrm{~mm} / \mathrm{d})$. (c) Percentile thresholds exceedance: percentiles are used to compute a precipitation threshold $P_{t}$, and the index is based on the frequency $F=1-g$ of exceedance. The three schematics assume daily precipitation distributions for a current and future climate (in blue and red, respectively), with the two distributions having a similar incidence of heavy events, but significantly different precipitation frequencies $(>1 \mathrm{~mm} / \mathrm{d})$. For display purposes, comparatively low percentiles have been selected, i.e. $80 \%$ in (a) and (c), $60 \%$ in (b). For definition of symbols see text. The resulting precipitation percentiles or frequencies (for a selected probability or precipitation threshold, respectively) are indicated by blue and red bullets. Panel (a) exhibits a decrease in precipitation percentile when changing from blue to red distribution, and panel (c) a consistent decrease in threshold exceedance. In panel (b) there is an artificial increase of the wet-day percentile due to decreases in wet-day fraction 


\subsection{All-day percentile indices}

For illustration, Fig. 1 assumes two precipitation distributions (shown in blue and red) representing hypothetical current and future climatic conditions, respectively. For simplicity we consider a change where the event size (intensity $P$ ) decreases throughout the event spectrum from current to future conditions. The two distributions are assumed to have a similar incidence of heavy events, but significantly different precipitation frequencies (defined as days with precipitation exceeding a threshold of $1 \mathrm{~mm} / \mathrm{d}$ ). For display purposes, comparatively low percentiles are selected (i.e. $80 \%$ in Fig. 1a), but this choice does not affect the argument.

In the case of all-day percentiles, all (wet and dry) events are included in the statistics (see Fig. 1a). All-day percentile indices thus represent the intensity of some $n$ largest events per season/year, and they correspond to events with an absolute frequency or return period. Changes in all-day percentiles may be expressed as $\delta P(g)=P^{\prime}(g)-P(g)$, where $P(g)$ and $P^{\prime}(g)$ denote the distributions for the current and future conditions, respectively.

\subsection{Wet-day percentile indices}

In the case of wet-day percentiles (Fig. 1b), days with precipitation below some threshold (here $1 \mathrm{~mm} / \mathrm{d}$ ) are considered as dry, and the percentiles are computed for the fraction of wet days. Changes in wet-day percentiles are affected by changes in both the occurrence of heavy events and the number of wet days. If there are substantial changes in wet-day fraction, the procedure may yield misleading results. For example, consider the wet-day 60th percentiles for current and future conditions in Fig. $1 \mathrm{~b}$ (represented by blue and red bullets, respectively). There is an increase in this percentile, which may be mistaken as an increase in heavy events - yet there is an evident decrease in intensity throughout the event spectrum (blue and red curves). This potentially misleading result is due to the use of a precipitation threshold in combination with significant changes in wet-day fraction.

Figure 1a and $\mathrm{b}$ underline the key point of this paper, namely that the interpretation of changes in wet-day percentiles is strongly sensitive to changes in wet-day fraction: This seemingly counter-intuitive sensitivity comes about because, in statistical parlance, wet-day percentiles are conditional upon the occurrence of a wet day. In our example, a reduction in wet-day frequency implies that the wet-day precipitation distribution is compressed across fewer events, and thus there is an increase in intensity conditional on the occurrence of a wet day, even though heavy events decrease. As a result, changes in wet-day percentiles implicitly compare intensities taken at different absolute probabilities. This contrasts with all-day percentiles (Fig. 1a), which are free of this complication.

The consideration of wet-day percentiles may, however, be useful to gain insight into changes of the precipitation intensity process in isolation from changes in the occurrence process. More specifically, one may argue that the frequency of precipitation events is determined by the sequence of synoptic-scale circulation patterns, while the event intensity is governed by underlying precipitation processes (see Fowler and Hennessy 1995; Frei et al. 2006; Lenderink and van Meijgaard 2008; Chan et al. 2015). However, if such arguments are applied to impact-relevant considerations, then the conditional nature of wet-day percentiles needs to be accounted for. This applies for instance to the assessment of precipitation scaling (e.g. in relation to the Clausius-Clapeyron effect) when addressing projections of heavy events (Ban et al. 2015). 
The relationship between changes in all-day and wet-day percentiles can be assessed analytically. To do so we consider the all-day cumulative precipitation distribution $P(g)$, and the corresponding wet-day cumulative precipitation distribution function $P_{w}\left(g_{w}\right)$. The probability variable $g$ measures probabilities relative to all days, while $g_{w}$ does so relative to wet days (see Fig. 1b).

A detailed mathematical analysis using a linearization is presented in the Appendix. To simplify the argument, we here assume that current and future precipitation distributions are identical at intermediate to high percentiles, but different at low percentiles and in terms of wet-day frequency $f_{w}$. This is qualitatively similar to the situation shown in Fig. 1 (see blue and red curves), but more pronounced, as the two distributions are assumed to be identical at high percentiles, i.e. $\delta P=0$.

To simplify the analysis we also assume that precipitation follows an exponential distribution locally, that is, near the intensity considered. The frequency $F$ of events exceeding intensity $P$ is assumed to decrease proportionally to $e^{-P / \beta}$, where $\beta>0$ is a scale parameter (see Appendix A1 for further details).

While the intensity of heavy precipitation events does not change under the current assumptions (i.e. $\delta P=0$ ), wet-day percentiles change following (A11) accordingly to

$$
\frac{\delta P_{w}}{P_{w}} \approx-\frac{\beta}{P} \frac{\delta f_{w}}{f_{w}}
$$

where $\delta f_{w} / f_{w}$ and $\delta P_{w} / P_{w}$ denote relative changes in wet-day frequency and wet-day percentiles, respectively. This is a remarkably simple result, stating that even in absence of changes in all-day percentiles (i.e. $\delta P=0$ ), there may be changes in wet-day percentiles. These are equal to minus the product of the relative changes in wet-day frequency $\delta f_{w} / f_{w}$ and the normalized scale parameter $\beta / P$.

It should be noted that in order to consider events of the same frequency (or return period), some adjustment may be needed when objectively comparing wet-day against all-day percentiles. For instance, in the example considered in Fig. 1, the 80th all-day percentile and the 60th wet-day percentiles correspond to roughly the same event frequency (see Appendix A3 for details).

\subsection{Frequency indices}

To finalize the analysis we next consider indices that assess the frequency of exceedance with respect to a precipitation threshold. Many studies define precipitation thresholds using percentiles; such indices are commonly referred to as percentile indices (e.g. WMO 2009), but they represent frequency indices.

Figure 1c illustrates the analysis. In the example shown the precipitation threshold $P_{t}$ is defined as the 80th all-day percentile, but the subsequent discussion is valid irrespective of how the threshold is defined, provided the threshold is kept fixed throughout the analysis (i.e. the same absolute threshold is used in both the control and scenario periods; see Zhang et al. 2011, for details on the threshold calculation).

In contrast to the full percentile methodology (subsection 2.1) the procedure measures changes in threshold exceedance frequency $F$, rather than changes in event size $P$ (compare $\mathrm{red} / \mathrm{blue}$ bullets in Fig. 1c against 1a). For this reason, the methodology does not fully classify as a percentile methodology; it rather corresponds to a frequency methodology, but using a percentile-based definition of the thresholds. 
Following (A13), relative changes in all-day percentiles $\delta P / P$ and threshold exceedance $\delta F /$ $F$ are approximately linked by

$$
\frac{\delta P}{P} \approx \frac{\beta^{\prime}}{P} \frac{\delta F}{F}
$$

Here $\beta^{\prime}$ is the scale parameter of the scenario distribution $P^{\prime}(g)$. Equation (2) shows, consistent with Fig. 1a and c, that increases in all-day percentiles at a given probability level go along with increases in frequency at the respective percentile threshold, and vice versa. Thus frequency indices yield similar information as all-day percentiles, but are quantitatively different. It is important to note that the above considerations are valid irrespective of how the thresholds are determined. In particular, they also apply to other types of frequency indices.

In quantitative terms, (2) can be used to approximately convert between the indices. This requires estimating the factor $\beta$ ' $/ P$ from the precipitation distribution. For instance, using 10 years of precipitation data for Zurich, we find that $\beta / P$ has values between approximately 0.2 and 0.5 for daily precipitation between the 70th and 98 th percentile. Thus, relative changes in frequency will be larger than relative changes in percentiles.

\section{Examples using climate models}

To investigate the quantitative role of different percentile index definitions, we proceed by giving consideration to end-of-century precipitation projections from global and regional climate model simulations. In all figures presented, panels $(\mathrm{a}-\mathrm{c})$ will refer to the three indices considered in Fig. 1a-c, respectively.

\subsection{Analyses of GCM simulations}

We begin with an analysis of daily precipitation events from the CMIP5 model experiments (Taylor et al. 2012). Following Fischer et al. (2014) we present ensemble-mean results based on 20 CMIP5 model simulations. Figure $2 d$ depicts the wet-day fraction in the control period. Anthropogenic forcing causes substantial changes in wet-day fraction over large areas (Fig. 2e). The wet-day frequency increases in the tropics and high latitudes, and decreases in the subtropics and some of the extratropics (cf. Polade et al. 2014). These projected changes have appreciable magnitude. For instance, relative changes in wet-day fraction exceed $+30 \%$ in the equatorial Pacific and $-30 \%$ in Southern Europe and the Mediterranean.

Figure $2 \mathrm{a}$ and $\mathrm{b}$ show projected changes in all-day and wet-day percentiles of daily precipitation. The two percentile analyses show pronounced differences. For example: changes in wet-day percentiles (Fig. 2b) signal significant increases in heavy precipitation events in Southern Europe, while all-day percentiles signal substantial decreases (Fig. 2a). This discrepancy is due to the conditional nature of wet-day percentiles, which may produce artifacts in areas with decreasing wet-day fraction. Qualitatively similar discrepancies are also evident for South Africa and Australia. The opposite effect can be observed at high latitudes. Here there are substantial increases in wet-day fraction (cf. Fig. 2e), and wetday percentiles significantly underestimate the increases in heavy events (compare Fig. 2a and $b$ ). 

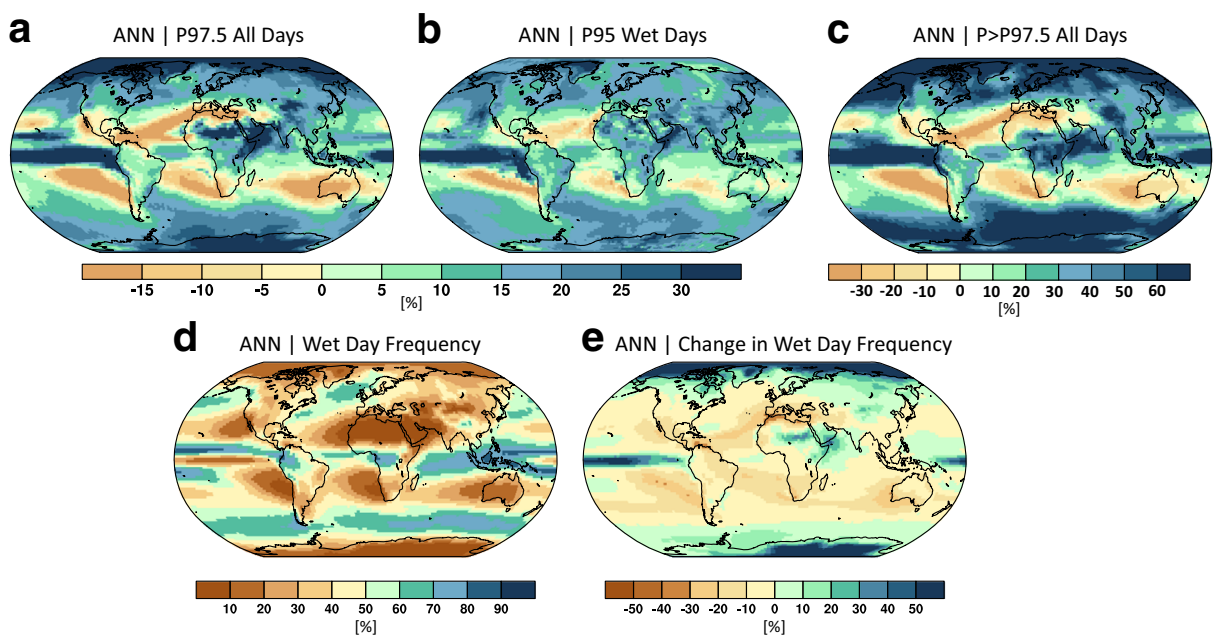

Fig. 2 Impact of percentile definition on projected changes in heavy precipitation events. Results show annualmean ensemble means 2071-2100 versus 1976-2005 for 20 CMIP5 models using the RCP8.5 emissions scenario. Upper panels show relative changes of (a) all-day percentiles, (b) wet-day percentiles, and (c) frequency of exceedance of an all-day percentile threshold. Lower panels show (d) wet-day fraction based on a precipitation threshold of $1 \mathrm{~mm} / \mathrm{d}$ in the period 1976-2005, and (e) relative change in wet-day fraction. The wet-day percentile index in (b) is relative to the sample of wet days, and for comparison a lower percentile level is selected, so as to match the event size for regions with a wet-day fraction of about $50 \%$ (e.g. Central and Southern Europe)

It should be stressed that Fig. 2a and b are not directly comparable, as they address different event levels (as determined by the selected percentiles of the all-day and wet-day distributions). In order to improve the comparison for events of similar probability (or return period), consideration was given to different percentiles. More specifically, Fig. 2a and b show the 97.5th and the 95th percentiles, respectively, which yields a perfect comparison for all locations where the wet-day frequency is $50 \%$ (see Appendix A3).

Figure $2 \mathrm{c}$ presents relative changes in threshold exceedance frequency. Here the threshold is determined as the 97.5th all-day percentile. Changes in this index exhibit the same pattern as all-day percentiles (Fig. 2a), but the amplitude of the changes is much larger (note different scale). These differences are consistent with the theoretical analysis in Section 2.3. The differences arise from the fact that Fig. 2a represents an intensity index, while Fig. 2c represents a frequency index (i.e. the index is determined as the exceedance frequency with respect to a threshold).

\subsection{Analyses of RCM simulations over Europe}

Following Rajczak et al. (2013), consideration is given to a subset of 10 RCM simulations of the ENSEMBLES project (van der Linden and Mitchell 2009). Figure 3a-c shows projections using the same indices as in Fig. 2a-c. In addition, Fig. 3d-e show relative changes of 20 -year return values (based on Rajczak et al. 2013), and in terms of the Rx1d index (which is computed as the mean of the 30 seasonal maxima of daily precipitation). The relative change in wet-day frequency is shown in Fig. 3f.

The comparison of all-day and wet-day percentiles in Fig. 3a-b confirms the discrepancies expected from the previous discussion. While all-day percentiles (Fig. 3a) exhibit significant 
Fig. 3 Upper panels as Fig. 2a-c, but for projections of heavy summer precipitation in RCM simulations over Europe. Results show ensemble means 2070-2099 versus 1970-1999 over 10 RCM simulations from the ENSEMBLES project, using a computational resolution of about $25 \mathrm{~km}$ and the SRES A1B emissions scenario. Lower panels show changes in (d) 20-yr return levels, (e) mean seasonal maximum one-day precipitation, and (f) wet-day frequency (based on a threshold of 1 $\mathrm{mm} / \mathrm{d}$ ). Stippling denotes grid points where 9 out of 10 RCMs agree on the sign of change. Estimates in (d) over the Mediterranean are not very robust, due to the small number of precipitation days
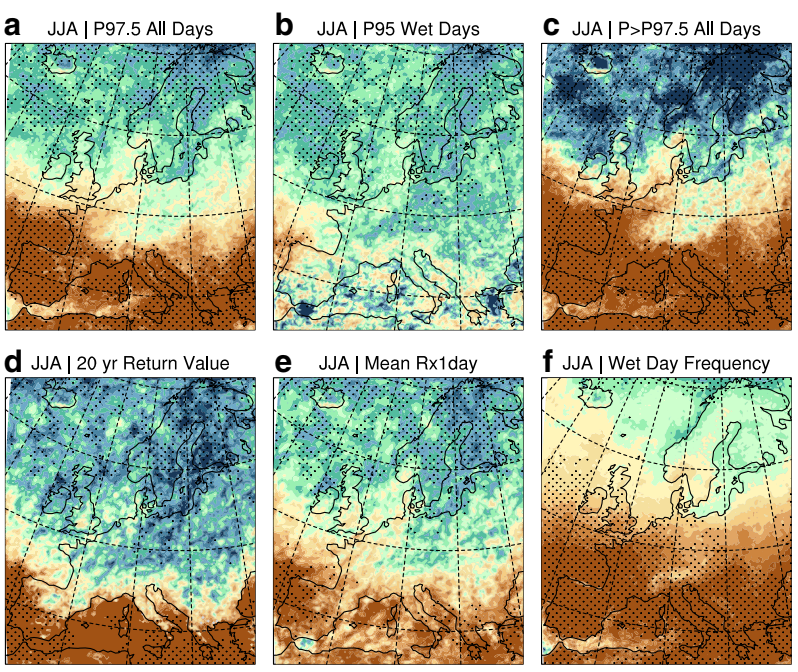

f JJA | Wet Day Frequency

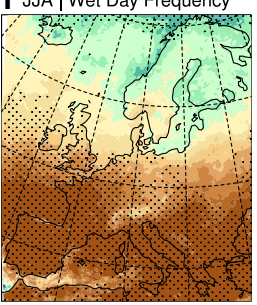

[\%]

decreases in the incidence of heavy precipitation events throughout southern Europe, wet-day percentiles (Fig. 3b) project slight increases. This potentially misleading result is due to the projected decrease in the fraction of wet days (Fig. 3f), which exceeds $30 \%$ in Southern Europe. In contrast, the pattern and amplitude of the changes in all-day percentiles (Fig. 3a) is fairly consistent with the changes in return levels and Rx1d index (see Fig. 3d-e). Some differences exist over France, England and Southeast Europe, where there is a sign change from moderate (97.5th all-day percentile) to heavy extremes (20-year return period). However, overall a coherent picture emerges: all-day percentiles (at sufficiently high level) are consistent with EVT, while wet-day percentiles yield different results.

Comparison of the percentile threshold indices (Fig. 3c) against all-day percentiles (Fig. 3a) reveals similar characteristics as previously seen in Fig. 2. In particular the two indices exhibit the same pattern but different amplitudes. Further analysis shows that the differences in amplitude depend significantly upon the region; they are largest in Scandinavia and over the British Isles, but small over the Mediterranean. This can be explained by differences in precipitation statistics in the different regions, as expressed by the factor $\beta^{\prime} / P$ in (2).

\subsection{Analyses of km-scale RCM simulations over the Alps}

We finish the discussion with an intercomparison of percentile indices in very high-resolution climate change projections. The simulations cover an extended Alpine area from Northern Italy to Northern Germany at a grid spacing of $2.2 \mathrm{~km}$ and are 10 years long (Ban et al. 2014). Climate change projections using this approach are presented in Ban et al. (2015); the inconsistencies between all-day and wet-day percentiles actually surfaced when preparing that paper.

As the modeling approach is able to explicitly resolve deep convective precipitation, consideration can be given to both daily (Fig. 4, top panels) and hourly accumulations (bottom panels). When computing wet-day and wet-hour percentiles, thresholds of $1 \mathrm{~mm} / \mathrm{day}$ and $0.1 \mathrm{~mm} / \mathrm{h}$, respectively, are used to define the occurrence of precipitation. The two left-hand 

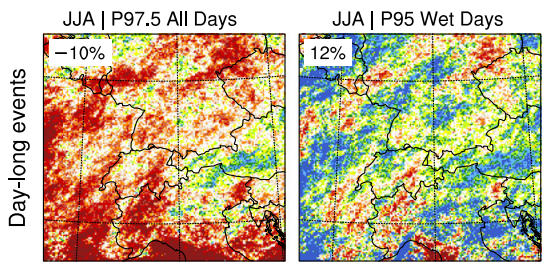

JJA $\mid$ P > P95 Wet Days

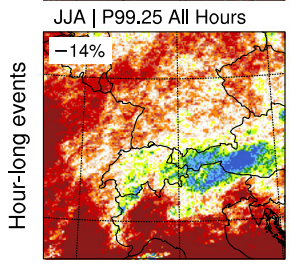

JJA | P95 Wet Hours

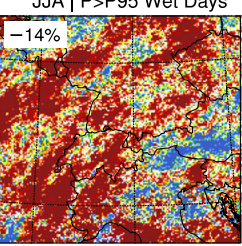

JJA | P>P95 Wet Hours
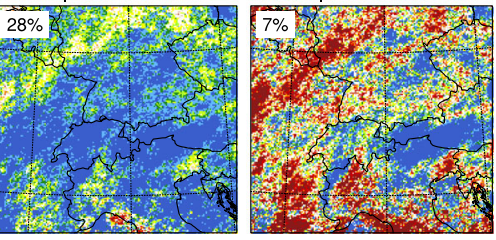

$\begin{array}{llllllllll}-30 & -20 & -15 & -10 & -5 & 5 & 10 & 15 & 20 & 30\end{array}$

$[\%]$

Fig. 4 Upper panels as Fig. 2a-c, but for projections of heavy summer precipitation from high-resolution RCM simulations over the Alps for 2081-2090 versus 1991-2000, using an RCP8.5 emissions scenario. The simulations cover an extended Alpine with a computational resolution of $2.2 \mathrm{~km}$. Upper and lower panels are for daily and hourly events, respectively. All-day/hour percentile changes are expressed at higher levels (for daily events P97.5) than the wet-day/hour percentile changes (P95), in order to compare events of similar size. Domain-mean values of relative changes are displayed in the upper-left corners of the panels

columns show a comparison of all-day/hour versus wet-day/hour percentile changes. The comparison reveals pronounced discrepancies for both daily and hourly events. For daily events, all-day percentiles signal an area-mean decrease of $10 \%$ (see numbers in the upper-left corners of the panels), but wet-day percentiles a $12 \%$ increase. For hourly events the discrepancies are even larger: all-hour percentiles signal a decrease of $14 \%$, but wet-hour percentiles a strong $28 \%$ increase. The larger discrepancies in terms of hourly events are due to the larger relative decrease of the wet-hour fraction (in comparison to the decrease in wetday fraction). The analysis demonstrates that changes in wet-day and wet-hour percentile indices may be strongly misleading.

The comparison of all-day percentiles (column 1) against frequency indices (column 3) is also of interest. Consistent with Section 2.3, the two indices yield the same spatial patterns, but with substantially different amplitudes. The analysis thus confirms that both all-day percentiles and frequency indices yield valid and consistent information about changes in heavy precipitation events, while there are quantitative differences between the two indices.

Note that in the case of the hourly analysis we have compared the 99.25th all-hour percentile against the 95 th wet-hour percentile. This choice is based on the wet-hour frequency, which on average is substantially smaller than the wet-day frequency ( $8 \%$ in comparison to $29 \%$ in domain mean, higher over the Alps). Thus for comparing hourly indices, Eq. (A14) should not be used, but rather consideration should be given to using (A1) with a characteristic value of the wet-hour frequency.

\section{Conclusions}

We have investigated three precipitation percentile indices that are commonly used in order to assess trends and projections of heavy precipitation events. Results show that wet-day 
percentiles (which are expressed relative to the fraction of wet events) are very sensitive to changes in the fraction of wet days/hours, and may produce misleading results when used to address changes in heavy precipitation events. The analysis of climate model output in section 3 demonstrates that this is critically important in typical climate change applications (for instance, an increase in wet-day percentiles does not necessarily reflect an increase in event intensity).

More generally, statements that are conditional upon the occurrence of wet days/hours (which may itself be changing), are difficult to interpret. Also, it does not appear logical to use indices that are sensitive to the occurrence of weak events (i.e. drizzle) when assessing heavy events (i.e. downpours). Wet-day percentiles suffer from these complications and should thus not be used for the impact-oriented assessment of changes in heavy precipitation events. Nevertheless, there are some appropriate applications of wet-day percentiles, such as studies that require conditional (wet-day/hour) probabilities to investigate precipitation scaling with temperature. However, when extrapolating such scaling considerations to a future climate, changes in precipitation frequency need to be taken into account.

There are several alternatives to wet-day percentile indices:

- All-day percentiles: These indices are computed from all data (wet and dry events) and describe intensity changes at a given absolute frequency (or return period). These percentiles may be viewed as an alternative to more sophisticated statistical approaches (i.e. extreme value theory, EVT) in the case of moderate extremes.

- Frequency indices: These indices describe the frequency of exceedance with respect to a precipitation threshold (that must be fixed throughout the analysis period or across control and scenario periods). This methodology has been recommended by the WMO. While these indices are often referred to as percentile indices (when the thresholds are defined using percentiles), they do not assess changes in intensity, but rather in frequency. Changes in these indices qualitatively agree with changes in all-day percentiles, but the amplitudes of frequency and intensity changes generally differ.

- Extreme value theory: Many societally relevant extremes have return periods of at least 10 years. The appropriate treatment of these events requires a more thorough statistical assessment that ideally should include some uncertainty assessment. A number of EVT methodologies (such as block-maxima and peak-over-threshold) are available for this purpose. The estimation of return levels / periods following these methodologies does not depend upon the specification of a minimum precipitation threshold. EVT is used extensively in water-resource engineering, and is well suited when using climate simulations to provide advice about climate change adaptation.

Our study also provides equations that can in principle be used to convert between the different percentile indices. However, the conversion involves some approximation and requires knowledge about the precipitation distribution. In practice it will often be easier to redo the analysis for the desired index.

In summary, our study shows that significant differences exist between different percentile methodologies. While the overall message of the scientific literature is quite clear and points towards an intensification of heavy events in many regions in response to greenhouse gas forcing, our results show that quantitative information about climate changes critically depend upon careful interpretation of the indices considered. 
Acknowledgments We acknowledge the World Climate Research Programme's Working Group on Coupled Modeling, and the EU-FP6 project ENSEMBLES, for providing access to the CMIP5 and ENSEMBLES data, respectively. We also acknowledge constructive comments and suggestions from Hayley Fowler (Newcastle University), Reto Knutti and Linda Schlemmer (both ETH Zurich) on earlier versions of this manuscript. The work of Nikolina Ban and Jan Rajczak was supported by the Swiss National Science Foundation (through the PhD grant 200021_132614 and the Sinergia grant CRSII2_136279 “TEMPS"). Elizabeth J. Kendon gratefully acknowlēges funding from the Joint DECC/ Defra Met Office Hadley Centre Climate Programme (GA01101). Jana Sillmann is supported by the Norwegian Research Council through the NAPEX project (no. 229778).

\section{Appendix: Theoretical analysis}

\section{A1. All-day versus wet-day percentiles}

Let us consider an all-day cumulative precipitation distribution $P(g)$ where $g$ is the all-day probability variable (as defined in Fig. 1 and section 2.1). The probability $g$ is taken with respect to all (wet and dry) days. Wet days are defined using a wet-day precipitation threshold (i.e. $1 \mathrm{~mm} / \mathrm{d}$ ), and the frequencies of wet and dry days are denoted with $f_{w}$ and $f_{d}$, respectively.

Let $g_{w}$ denote the conditional wet-day probability (i.e. the conditional probability relative to wet events $\geq 1 \mathrm{~mm} / \mathrm{d}$ ). The two probabilities $g$ and $g_{w}$ are linearly related to each other (see Fig. 1b). In particular, for $g_{w}=0$ we have $g=f_{d}$, and for $g_{w}=1$ we have $g=1$. More generally, the two probabilities are related through

$$
g_{w}=\left(g-f_{d}\right) / f_{w} \quad \text { and } \quad g=f_{d}+f_{w} g_{w}
$$

The cumulative wet-day precipitation distribution $P_{w}\left(g_{w}\right)$ can then be used similarly as $P(g)$, but it expresses the conditional probability relative to wet days. In the following the two functions $P_{w}\left(g_{w}\right)$ and $P(g)$ are used to describe the same precipitation distribution, but using different probability variables.

Next let us assume a change in the precipitation distribution from $P(g)$ to $P^{\prime}(g)$ with

$$
P^{\prime}(g)=P(g)+\delta P(g) \text { and } P_{w}^{\prime}\left(g_{w}\right)=P_{w}\left(g_{w}\right)+\delta P_{w}\left(g_{w}\right)
$$

corresponding to the changes from a control to a scenario climate. The corresponding changes in wet and dry-day frequencies are denoted as

$$
f_{w}{ }^{\prime}=f_{w}+\delta f_{w} \quad \text { and } \quad f_{d}{ }^{\prime}=f_{d}+\delta f_{d}
$$

with $\delta f_{d}=-\delta f_{w}$.

The change in wet-day percentiles between the two climate states is

$$
\delta P_{w}\left(g_{w}\right)=P_{w}^{\prime}\left(g_{w}\right)-P_{w}\left(g_{w}\right)
$$

where, consistent with the definition of wet-day percentile indices, a fixed wet-day probability $g_{w}$ is used (thus implying different all-day probabilities, see Fig. 1b). To compare this against changes in all-day percentiles $\delta P(g)$, we switch to the unconditional probability variable $g$. This yields

$$
\delta P_{w}\left(g_{w}\right)=P^{\prime}\left(g^{\prime}\right)-P(g)
$$


where $g^{\prime}=\dot{f}_{d}+\dot{f}_{w} g_{w}$ and $g=f_{d}+f_{w} g_{w}$ from (A1). The first term on the right-hand side of (A5) is expressed using a Taylor expansion

$$
P^{\prime}\left(g^{\prime}\right) \approx P^{\prime}(g)+\frac{\partial P^{\prime}}{\partial g} \delta g \approx P^{\prime}(g)+\frac{\partial P^{\prime}}{\partial g} \frac{\partial g}{\partial f_{w}} \delta f_{w}
$$

With $g=f_{d}+f_{w} g_{w}=\left(1-f_{w}\right)+f_{w} g_{w}=1-\left(1-g_{w}\right) f_{w}$ one finds

$$
\frac{\partial g}{\partial f_{w}}=-\left(1-g_{w}\right)=-\frac{1-g}{f_{w}}
$$

where we have replaced the term $\left(1-g_{w}\right)$ with (A1). Substitution into (A6) and then (A5) yields

$$
\delta P_{w}\left(g_{w}\right) \approx \delta P(g)-\frac{\partial P^{\prime}}{\partial g}(1-g) \frac{\delta f_{w}}{f_{w}}
$$

This equation relates changes in wet-day percentile intensities with changes in all-day percentile intensities.

Upon assuming a change with locally identical distributions $\delta P=0$ near the percentile considered, but still allowing for changes in wet-day frequency $\delta f_{w}$, one finds

$$
\delta P_{w}\left(g_{w}\right) \approx-\frac{\partial P}{\partial g}(1-g) \frac{\delta f_{w}}{f_{w}}
$$

This shows and quantifies that a decrease (increase) in wet-day frequency mimics an artificial increase (decrease) in $\delta P_{w}$, even in cases where the distributions at high percentiles are identical, i.e. $\delta P(g)=0$.

To refine the analysis, one can use a simple parametric representation of $P(g)$. The simplest possibility is the exponential distribution (which is a special case of the commonly used gamma distribution, see e.g. Gregory and Mitchell 1995). The exponential distribution expresses the frequency $F$ of events exceeding intensity $P$ as

$$
F(P)=a e^{-P / \beta}
$$

where $\beta$ denotes the scale, and $a$ an amplitude parameter. Although the exponential distribution is generally a rather poor fit to daily precipitation distributions, it is locally (i.e. near some value of $P$ or $g$ that is of interest) a reasonable approximation. Upon noting that $F=1-g$, Eq. (A9) may be inverted to

$$
P(g)=-\beta \ln (1-g)+C
$$

where $C$ denotes some constant. Introducing this expression into (A8) yields

$$
\delta P_{w}\left(g_{w}\right) \approx-\beta \frac{\delta f_{w}}{f_{w}}
$$

\section{A2. All-day percentile versus frequency indices}

Following section 2.3 we next assume that the frequency of exceedance of some fixed precipitation threshold $P_{t}$ is taken as indicator of changes in heavy precipitation. As with many applications of this methodology, we assume that $P_{t}$ is defined as some percentile of the 
reference period, i.e. $P_{t}=P\left(g_{t}\right)$, where $g_{t}$ denotes the relevant probability level. The situation is sketched in Fig. 1c.

Using a linearization, changes in percentiles and frequency of exceedance can be related using the relationship

$$
\left.\frac{P\left(g_{t}\right)-P^{\prime}\left(g_{t}\right)}{g^{\prime}-g_{t}} \approx \frac{\partial P^{\prime}}{\partial g}\right|_{g_{t}}
$$

Here we use the same notation as above, i.e. $P^{\prime}(g)$ denotes the percentiles of the scenario distribution, and $g$ ' the probability of scenario for precipitation to stay below $P_{t}$. Next we again assume an exponential precipitation distribution (A10) and use $F=1-g$ to find

$$
\delta P \approx \beta^{\prime} \frac{\delta F}{F}
$$

Here $\beta^{\prime}$ denotes the scale of the scenario distribution, and $\delta F / F=\left(F^{\prime}-F\right) / F$ the relative change in the frequency of exceedance.

\section{A3. Comparing wet-day and all-day percentiles}

When comparing all-day and wet-day percentiles, one would ideally like to do so at the same absolute probability level $g$ (or at the same return period). Some care is thus needed, as in general $g_{w} \neq g$. For instance, Fig. $3 \mathrm{a}$ and b compare percentiles at cumulative all-day and wetday probabilities of $g=97.5 \%$ and $g_{w}=95 \%$, respectively. The argument behind this rescaling is evident from (A1).

The linkage (A1) between the two probability variables depends upon dry-day and wet-day frequencies $f_{d}$ and $f_{w}$. For the comparison in Fig. 3, one may approximately use $f_{d}=f_{w}=0.5$, and with (A1) this yields

$$
g=\left(1+g_{w}\right) / 2
$$

This relationship is recommended, unless the precipitation frequency significantly differs from $f_{w}=0.5$. In particular, for hourly precipitation events or special climatic conditions, other choices may be optimal.

Open Access This article is distributed under the terms of the Creative Commons Attribution 4.0 International License (http://creativecommons.org/licenses/by/4.0/), which permits unrestricted use, distribution, and reproduction in any medium, provided you give appropriate credit to the original author(s) and the source, provide a link to the Creative Commons license, and indicate if changes were made.

\section{References}

Allen MR, Ingram W (2002) Constraints on future changes in climate and the hydrologic cycle. Nature 419:224 232

Ban N, Schmidli J, Schär C (2014) Evaluation of the convection-resolving regional climate modelling approach in decade-long simulations. J Geophys Res Atmos 119:7889-7907

Ban N, Schmidli J, Schär C (2015) Heavy precipitation in a changing climate: does short-term summer precipitation increase faster? Geophys Res Lett 42. doi:10.1002/2014GL062588 
Boroneant C, Plaut G, Giorgi F, Bi X (2006) Extreme precipitation over the Maritime Alps and associated weather regimes simulated by a regional climate model: present-day and future climate scenarios. Theor Appl Climatol 86(1-4):81-99

Chan SC, Kendon EJ, Roberts NM, Fowler HJ, Blenkinsop S (2015) Downturn in scaling of UK extreme rainfall with temperature for future hottest days. Nature Geosci, in press. doi: 10.1038/NGEO2596

Durman CF, Gregory JM, Hassell DC, Jones RG, Murphy JM (2001) A comparison of extreme European daily precipitation simulated by a global and a regional climate model for present and future climates. Q J Roy Meteorol Soc 127(573):1005-1015

Fischer EM, Sedlacek J, Hawkins E, Knutti R (2014) Models agree on forced response pattern of precipitaton and temperature extremes. Geophys Res Lett 41. doi:10.1002/2014GL062018

Fowler AM, Hennessy KJ (1995) Potential impacts of global warming on the frequency and magnitude of heavy precipitation. Nat Hazards 11:283-303

Fowler HJ, Ekström M, Blenkinsop S, Smith AP (2007) Estimating change in extreme European precipitation using a multimodel ensemble. J Geophys Res 112, D18104

Frei C, Schär C (2001) Detection probability of trends in rare events: theory and application to heavy precipitation in the Alpine region. J Clim 14:1568-1584

Frei C, Schär C, Lüthi D, Davies HC (1998) Heavy precipitation processes in a warmer climate. Geophys Res Lett 25:1431-1434

Frei C, Schöll R, Schmidli J, Fukutome S, Vidale PL (2006) Future change of precipitation extremes in Europe: an intercomparison of scenarios from regional climate models. J Geophys Res 111, D06105

Giorgi F, Coppola E, Raffaele F (2014) A consistent picture of the hydroclimatic response to global warming from multiple indices: models and observations. J Geophys Res Atmos 119:11,695-11,708

Gordon HB, Whetton PH, Pittock AB, Fowler AM, Haylock MR (1992) Simulated changes in daily rainfall intensity due to the enhanced greenhouse effect: implications for extreme rainfall events. Clim Dyn 8:83102

Gregory JM, Mitchell JFB (1995) Simulation of daily variability of surface temperature and precipitation over Europe in the current and $2 \cdot \mathrm{CO} 2$ climates using the UKMO model. Q J Royal Meteorol Soc 121:14511476

Groisman PY, Karl TR, Easterling DR, Knight RW, Jamason PF, Hennessy KJ, Suppiah R, Page CM, Wibig J, Fortuniak K, Razuvaev VN, Douglas A, Forland E, Zhai P-M (1999) Changes in the probability of heavy precipitation: important indicators of climatic change. Clim Chang 43:243-283

Haylock M, Nicholls N (2000) Trends in extreme rainfall indices for an updated high-quality data set for Australia, 1910-1998. Int J Climatol 20:1533-1541

Hennessy KJ, Suppiah R, Page CM (1999) Australian rainfall changes, 1910-1995. Aust Meteorol Mag 48:1-13

IPCC (2013) Summary for policymakers. In: Stocker TF, Qin D et al (eds) Climate change 2013: the physical science basis. Contribution of Working Group I to the Fifth Assessment Report of the Intergovernmental Panel on Climate Change. Cambridge University Press, Cambridge

Karl TR, Knight RW (1998) Secular trends of precipitation amount, frequency, and intensity in the United States. Bull Am Meteorol Soc 79:1107-1119

Kendon EJ, Roberts NM, Fowler HJ, Roberts MJ, Chan SC, Senior CA (2014) Heavier summer downpours with climate change revealed by weather forecast resolution model. Nat Clim Chang 4:570-576

Klein Tank AMG, Können GP (2003) Trends in indices of daily temperature and precipitation extremes in Europe. J Clim 16:3665-3680

Leander R, Buishand TA, Klein Tank AMG (2014) An alternative index for the contribution of precipitation on very wet days to the total precipitation. J Clim 27(4):1365-1378

Lenderink G, van Meijgaard E (2008) Increase in hourly precipitation extremes beyond expectations from temperature changes. Nat Geosci 1:511-514

Maraun D et al (2010) Precipitation downscaling under climate change: recent developments to bridge the gap between dynamical models and the end user. Rev Geophys 48, RG3003

Moberg A et al (2006) Indices for daily temperature and precipitation extremes in Europe analyzed for the period 1901-2000. J Geophys Res Atmos 111(D22), D22106

Noda A, Tokioka T (1989) The effect of doubling of CO2 concentration of convective and non-convective precipitation in a general circulation model coupled with a simple mixed layer ocean model. J Meteorol Soc Jpn 67:1057-1069

O'Gorman PA (2014) Contrasting responses of mean and extreme snowfall to climate change. Nature 512:416418

O'Gorman PA, Schneider T (2009) The physical basis for increases in precipitation extremes in simulations of 21st-century climate change. PNAS 106(35):14773-14777

Orlowsky B, Seneviratne SI (2012) Global changes in extreme events: regional and seasonal dimension. Clim Chang 110:669-696 
Polade S, Pierce D, Cayan DR, Gershunov A, Dettinger MD (2014) The key role of dry days in changing regional climate and precipitation regimes. Sci Rep 4, 4364

Räisänen J, Joelsson R (2001) Changes in average and extreme precipitation in two regional climate model experiments. Tellus 53A:547-566

Rajczak J, Pall P, Schär C (2013) Projections of extreme precipitation events in regional climate simulations for Europe and the Alpine region. J Geophys Res Atmos 118:3610-3626

Sillmann J, Kharin VV, Zwiers FW, Zhang X, Bronaugh D (2013) Climate extremes indices in the CMIP5 multimodel ensemble: Part 2. Future climate projections. J Geophys Res Atmos 118:1-21

Suppiah R, Hennessy KJ (1998) Trends in total rainfall, heavy rain events and number of dry days in Australia, 1910-1990. Int J Climatol 10:1141-1164

Taylor KE, Stouffer RJ, Meehl GA (2012) A summary of the CMIP5 experiment design. Bull Am Meteorol Soc 93:485-498

van der Linden P, Mitchell JFB (2009) Climate change and its impacts: summary of research and results from the ENSEMBLES project, 160 pp. MetOffice Hadley Centre, Exeter

Voss R, May W, Roeckner E (2002) Enhanced resolution modeling study on anthropogenic climate change: Changes in extremes of the hydrological cycle. Int J Climatol 22:755-777

WMO (2009) Guidelines on analysis of extremes in a changing climate in support of informed decisions for adaptation. Klein Tank AMG, Zwiers FW, Zhang X (ed). WCDMP No. 72, WMO-TD No. 1500, 52pp

Zhang X, Alexander L, Hegerl GC, Jones P, Klein Tank A, Peterson TC, Trewin B, Zwiers FW (2011) Indices for monitoring changes in extremes based on daily temperature and precipitation data. WIREs Clim Change 2: 851-870

Zolina O, Simmer C, Belyaev K, Kapala A, Gulev S (2009) Improving estimates of heavy and extreme precipitation using daily records from European rain gauges. J Hydrometeorol 10:701-716

Zwiers FW, Kharin VV (1998) Changes in extremes of the climate simulated by CCC GCM2 under CO2 doubling. J Clim 11:2200-2222 